\title{
Poland tackles science like a business
}

Polish leaders were disconcerted in January, when the nation's scientists came away empty-handed from the first round of applications for the European Research Council's starting-grant competition. The country is also performing poorly in other European Union research programmes (see page 558). Science minister Barbara Kudrycka explains how the Polish government plans to reform the country's science and higher-education system.

\begin{abstract}
What are the strengths of the existing Polish science system?

We are among the top 20 science nations in fields such as physics, mathematics, chemistry and space. However, we are missing the opportunity to translate this potential into concrete business solutions. That is what we call the innovation gap, and it can best be seen in the number of patents granted in these areas.

But even in applied research there are fields where Polish researchers' performance is among the best in the European Union (EU). For instance, our share of grants awarded through the European research programmes in thematic priorities such as security is outstanding.
\end{abstract}

\section{What changes have been proposed?}

The biggest change is introducing

competitive mechanisms into the system. We want to implement them in the next few years wherever possible - from the distribution of research grants to the development of academic careers. One concrete idea is to create 'flagship' universities.

We also propose abandoning the Habilitation [a post- $\mathrm{PhD}$ qualification usually required for progress in academia].

\section{How will science in Poland benefit from the changes?}

Well, I would like to say that these changes will lead to Polish Nobel prizewinners, but that would be an overstatement. Our aim is to create excellent conditions for students and scientists in order to create a solid foundation for a knowledge-based society. What we can do from the political point of view is to create an appropriate framework and provide suitable incentives to make science flourish. Whether it does so is a matter for the scientific community itself.

The level of financing dedicated to research and higher education is meant to be increased substantially in the next few years. But these additional funds have to be spent effectively. That is why the whole system has to be better organized, with the ministry playing a strategic part and two funding agencies dealing with cutting-edge applied and basic research.

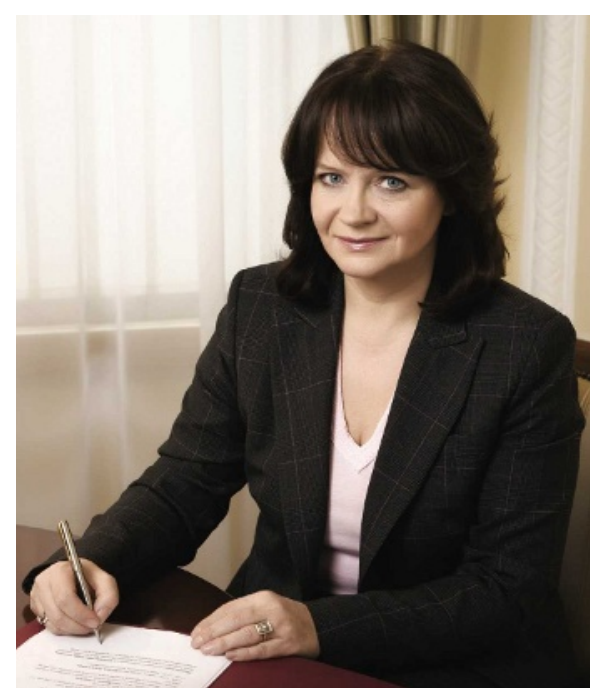

How much extra money will become available, and when?

Currently, budgetary expenditure on research and development (R\&D) and higher education amounts to little more than $1 \%$ of gross domestic product (GDP). We would like to increase funding by $0.15 \%$ of GDP per year until 2013. What is equally important is attracting private funds. Today Poland has one of the lowest R\&D expenditures financed by the business sector in the whole European Union. We are working on new legislative measures that will make investment in research more attractive for private companies.

\section{How will the money be distributed?}

Our National Science Council will provide funds for frontier research on a competitive basis. Those parts of the system that become competitive will receive extra funding. We want to reduce expenses where the results - scientific, economic or academic - are not evident whatsoever.

\section{Are you concerned that academia will try} to block the reform?

Everyone agrees that we should not only prevent talented young scientists from leaving our country but also attract them from abroad. At present, if an experienced professor from Oxford or Sydney wants to take up a post at a Polish university, they have to undergo a long and complex evaluation procedure simply because they don't have the proper scientific degree. Parts of the academic community are unenthusiastic about the proposed changes, such as abandoning the Habilitation. But Habilitation does not exist in most countries. If we want to become attractive we have to be open.

Are there any particular fields of science that you think should become priorities? The first priority will be advanced energy technologies. Work on strategic programmes for information and communication technologies and health are also to be concluded very soon.

How will the reform affect the role of the Polish Academy of Science?

Academy institutes should focus their research on selected areas of science that correspond to our national strategic and priority areas. Some of these institutes are outstanding, some are not that good. We plan to audit the institutes, after which only the best will survive.

What can be done to make Poland more attractive to young scientists, from Poland and from abroad?

This is a crucial problem for us. Abandoning the Habilitation could be helpful, but it is not enough. We would like to impose a system in which each position will be filled in an open, competitive, international process. Attractive postdoctoral fellowships should also be more accessible.

\section{Poland's participation in EU-funded research is modest at best. How can it be improved?}

Polish scientists often don't meet the direction and criteria of EU-funded research. It is not because of the quality, but the subject of the proposed projects that they are rejected. To gain more European grants, we need to modify the direction of our research so that it will respond to EU priorities. Interview by Quirin Schiermeier 